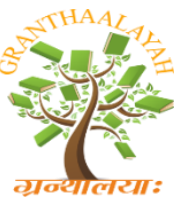

\author{
GRANTHAALAYAH \\ A knowledge Repository
}

INTERNATIONAL JOURNAL OF RESEARCH -

Science

\title{
CROSS-SECTIONAL STUDY ON EQUINE LUNG WORM AND ASSOCIATED RISK FACTOR IN AMBO DISTRICT, OROMIA REGION, ETHIOPOIA
}

\author{
Tolesa Negasa ${ }^{1}$, Tegegn Dilbato ${ }^{2}$, Daba Gudeta ${ }^{3}$ \\ 1,2, 3 Jimma University College of Agriculture and Veterinary Medicine, School of Veterinary \\ Medicine, Ethiopia
}

DOI: https://doi.org/10.29121/granthaalayah.v5.i5.2017.1862

\begin{abstract}
To determine the prevalence of lungworm, Dictyocacaulus arnifieldi and identify risk factors associated with occurrence of diseases in equines in and around Ambo town, in Oromia region, Ethiopia.

Equine lungworm, Dictyocacaulus arnifieldi is a parasitic disease that affects horses, donkeys and mules, is widespread in study area. The infection is transmitted by ingestion of contaminated pasture which contains infective stage larvae of Dictyocacaulus arnifieldi. To-date, effective control program still remains to be a reality and needs to be strengthened.

Purposive sampling technique was used to select study animals and performed using modified Berman technique in Ambo University veterinary laboratory technology. Descriptive statistics and logistic regression used to analyze using STATA statistical software version 9.

From the total 384 equines (donkeys, $n=313$, mules, $n=29$, and horses, $n=42$ ) the positive animal was 77 resulting the overall prevalence $20.1 \%$ equine lungworm. There is significance difference between Kebele (small admistrative unit), age, body condition and seasons of the study period $(\mathrm{p}<0.05)$.

The study suggests that the community of the study area was highly affected lungworm infection, Dictyocacaulus arnifieldi. Therefore, awareness should be created to the owners regarding the management system of equine was recommended.
\end{abstract}

Keywords: Lung Worm; Parasitic Disease; Dictyocacaulus arnifieldi.

Cite This Article: Tolesa Negasa, Tegegn Dilbat, and Daba Gudeta. (2017). "CROSSSECTIONAL STUDY ON EQUINE LUNG WORM AND ASSOCIATED RISK FACTOR IN AMBO DISTRICT, OROMIA REGION, ETHIOPOIA." International Journal of Research - Granthaalayah, 5(5), 312-319. https://doi.org/10.29121/granthaalayah.v5.i5.2017.1862. 


\section{Introduction}

Ethiopia has 1.91 million horses, 6.74 million donkeys, 0.35 million mules [1]. Equine (donkeys, mules and horses) play an important role as working animals in many parts of the world, for packing, riding, carting and sloughing and the same is true in Ethiopia especially in both rural and urban transport system. This is because of its cheapness and availability and so provides the best alternative transport means in places where the road network is insufficiently developed and the landscape is rugged and mountainous and in the cities where narrow streets prevent easy delivery of cars [2].

Even though mules, horses and donkeys have often been described as sturdy animals; they succumb to a variety of diseases and a number of other unhealthy circumstances. Among these, parasitic infection is a major cause of illness [3]. Different parasite has been reported to cause respiratory problem in equines [4]; [5]. Of these Dictyocalus species has been reported to be the major cause due to the fact that the equine is natural reservoir of the parasite and the parasite being ubiquitous in nature [6]; [4]; [7]. The genus Dictyocalus is live in the bronchi of cattle, sheep, horses, donkeys, mules and hinnies and has been found throughout the world. This genus has three species; D. viviparous, D. airfield and D. filarial, of these D. arnfieldi affect equines [6]; [8].

In horses its prevalence is difficult to establish since infection is rarely become patent, although it is frequently incriminated as the cause of chronic coughing and increase respiratory rate. However patent infection may develop in foals and these are not usually associated with clinical sign [6]. Donkeys acquire infection as foals and yearling and tend to remain infected, presumably through re-exposure all their lives. Young animal suffer more as compared to the older animals [6]; [9]. Patent infections usually establish during the first season at grazing and in the absence of anthelmintic therapy, the majority of animals subsequently remain infected throughout their live and act as the source of infection for other [10].

In donkeys and horses, adult parasite have been found in lungs throughout the year .In large study performed over one year in Kentucky, United states of America, lung Worm infected horses were found in each month of the study [8]. Another study by [11] also showed D.arnfieldi infection to be present through the year in Moroccan donkey with annual incidence of $47.8 \%$. A preliminary study conducted by [5] on the helimithosis of equine in south and north wollo zone reported $22.36 \%$ of examined donkeys $(n=331)$ and $8.89 \%$ of examined mules $(n=46)$ had $D$. arnfieldi. Although lungworms are known to be widely distributed in Ethiopia, documented studies are rare. A cross-sectional study conducted in north east Ethiopia by [12] showed an infection rate of $53.6 \%$ ante mortem examination and $66.3 \%$ by post-mortem examination. In Ethiopia $83 \%$ from six donkeys were reported to have been infected with $D$. arnfieldi [2].In study area there is mixed farming system and equine play essential role in the life of the farmer. They used for traditional sport, as ambulance for transportation of people, transportation of goods and water. But there is no research done on equine lung worm in Ambo woreda.

Therefore taking in to account of this parasite in equine, this study was targeted to fill the information gap in the area with the following objectives.

- To estimate the prevalence of lung worm infection in equine 
- To assess risk factor associated with lung worm

- To provide information on control and prevention of the disease.

\section{Materials and Methods}

\subsection{Study Area}

The study was conducted at Ambo town and its surrounding kebeles (small admistrative unit), west Showa Zone, Oromia Regional State, located at a distance of about $107 \mathrm{~km}$ from Addis Ababa to the west direction. The altitude of the area ranges from 1380-3330 meters above the sea level and receive annual rain fall 900 millimeters with average minimum and maximum temperature of $15^{\circ} \mathrm{c}$ and $29^{\circ} \mathrm{c}$ respectively. In study area there is mixed farming system and equine play essential role in the day to day life of the farmer and there is traditional management system of equine.

\subsection{Study Type and Study Population}

A cross- sectional study type was carried on the purposively selected 384 equine (42 horse, 313 donkey and 29 mule) found in and around Ambo town.

\subsection{Sample Size and Sampling Procedure}

The study type was cross- sectional and it was a simple random sampling technique used to select individual study animals. The desired sample size was calculated according to formula given by [13] at 50\% expected prevalence setting $95 \%$ confidence interval and a $\mathrm{P}$ value of less than 0.05 was taken as statistical significant. Therefore, the calculated sample size was 384 .

Study Methodology

Fecal samples were collected directly from the rectum of the animal using sterile glove and placed in sample a vial which was labeled accordingly and brought to the veterinary laboratory technology. Fecal samples were processed on the day of collection and fecal examination was performed using modified Berman technique as stated by [14].

Suring sampling some of the potential risk factors such as age, body condition and sex were collected. They were all local breeds, kept under extensive management system.

Data management and analysis

The data were recorded on specially designed forms and preliminary analysis was done in Microsoft Excel. The outcome variables were the cases of lungworm L1 larvae detected during the fecal examination (positive $=1$ or negative $=0$ ). Descriptive statistics was carried out to summarize the prevalence of the disease and proportion of infection in each species. Logistic regression analysis was conducted to see the association between the risk factors and the occurrence of the disease. Confidence interval and p- value was seen to see the presence of association and Odds Ratios was employed to assess the strength and direction of this association using STATA statistical software version 9. 


\section{Results}

Form the total 384 equines (donkeys, $n=313$, mules, $n=29$, and horses, $n=42$ ) the positive animal was 77 resulting the overall prevalence $20.1 \%$ equine lungworm. The prevalence in each species was found to be $18.2 \%, 24.1 \%$ and $31.0 \%$ in donkeys, mules and horses, respectively with no significance $(\mathrm{P}>0.05)$ association between them.

Table 1: The occurrence of the lungworm infection in equine

\begin{tabular}{lllll}
\hline Species & No tested & Number positive & Prevalence $(95 \% \mathrm{CI})$ & $\mathrm{X}^{2}$ (p-value) \\
\hline Donkey & 313 & 57 & $18.2(14.1,23.0)$ & \\
Mule & 29 & 7 & $24.1(10.3,43.5)$ & $4.1(0.128)$ \\
Horse & 42 & 13 & $31.0(17.6,47.1)$ & \\
Total & 384 & 77 & $20.1(16.1,24.4)$ & \\
\hline
\end{tabular}

The multivariable logistic regression analysis of the risk factors with the occurrence of lungworm infection indicated the presence of significant difference between the infection occurrence and kebeles, age, body condition score of the study animals and months of the study period $(\mathrm{p}<0.05)$. Hence, it was observed that the chance of occurrence of lungworm infection in kebele $3(\mathrm{p}=0.04, \mathrm{OR}=5,95 \% \mathrm{CI} 1,32)$, age between 8 and 11 years $(\mathrm{p}=0.00, \mathrm{OR}=7.695 \% \mathrm{CI}$ $=2.65 \% \mathrm{CI}=2.6,21.7)$, animals with poor body condition score $(\mathrm{p}=0.00, \mathrm{OR}=4.8,95 \% \mathrm{CI}$ $2.2,10.9)$ and in month of March $(\mathrm{p}=0.012$, OR $=7.6,95 \%$ CI 1.6, 32) than the rest of kebeles, age of less than 5 years, animals with good body condition score and the rest of the study period, respectively. One the other hand, there is no statistically significant difference in the prevalence of lungworm with species, work type and deforming history of the animals.

The univariate analysis revealed the existence of association between lungworm infection and sex of animals with the higher occurrence in males than females. Form 94 animals with cough were $46(48.9 \%)$ are positive for lungworm infection and from 290 animals with no cough were $31(10.7 \%)$ animals are positive for lungworm infection.

Table 2: Analysis of the risk factors with occurrence of lungworm infection in equine

\begin{tabular}{|c|c|c|c|c|c|c|}
\hline Risk factor & No tested & $\begin{array}{l}\text { Number } \\
\text { positive }\end{array}$ & $\begin{array}{ll}\text { Crude } & \text { OR } \\
(95 \% \mathrm{CI}) & \end{array}$ & P-value & $\begin{array}{l}\text { Adjusted } \\
\text { OR }(95 \% \mathrm{CI})\end{array}$ & $\mathrm{P}$ - value \\
\hline Kebele 1 & 75 & $13(17.3)$ & 1 & & 1 & \\
\hline 2 & 51 & $10(19.6)$ & $1.2(0.5,4.7)$ & 0.745 & $1.9(0.5,6.7)$ & 0.343 \\
\hline 3 & 42 & $5(11.9)$ & $1.6(0.5,4.7)$ & 0.431 & $5.1(1.1,23.0)$ & 0.041 \\
\hline Senkele & 70 & $20(28.6)$ & $2.0(0.8,4.2)$ & 0.109 & $1.2(0.4,3.8)$ & 0.712 \\
\hline Hawaro & 103 & $16(15.5)$ & $1.1(0.5,2.5)$ & 0.750 & $1.5(0.6,4.2)$ & 0.401 \\
\hline Gosu qora & 43 & $13(30.2)$ & $2.1(0.9,5.2)$ & 0.091 & $1.2(0.3,3.7)$ & 0.934 \\
\hline Sex Female & 209 & $29(16.3)$ & 1 & & 1 & \\
\hline Male & 175 & $43(24.6)$ & $1.7(1.2,8.1)$ & 0.040 & $1.2(0.6,2.8)$ & 0.600 \\
\hline Age $<5$ year & 101 & $29(28.7)$ & 1 & & 1 & \\
\hline 5-8 year & 130 & $20(15.4)$ & $2.2(1.2,4.2)$ & 0.020 & $3.6(1.4,9.6)$ & 0.009 \\
\hline 8-11 year & 118 & $21(17.8)$ & $1.9(1.0,3.5)$ & 0.061 & $7.6(2.6,21.7)$ & 0.000 \\
\hline$>11$ year & 35 & $7(20.0)$ & $1.6(0.6,4.0)$ & 0.301 & $7.3(1.7,28.0)$ & 0.006 \\
\hline
\end{tabular}




\begin{tabular}{|c|c|c|c|c|c|c|c|}
\hline Deworm & No & 269 & $57(21.2)$ & 1 & & 1 & \\
\hline & Yes & 115 & $19(16.5)$ & $1.3(0.8,2.4)$ & 0.301 & $1.4(0.5,2.1)$ & 0.990 \\
\hline Body co & ndition & & & & & & \\
\hline Good & & 90 & $29(14.0)$ & 1 & 0.010 & 1 & 0.432 \\
\hline Medium & & 87 & 16.(18.4) & $2.4(1.2,4.9)$ & 0.000 & $1.5(0.6,3.6)$ & 0.000 \\
\hline Poor & & 207 & $32(35.5)$ & $3.3(1.9,6.0)$ & & $4.8(2.2,10.9)$ & \\
\hline Work & type & 28 & $7(25.0)$ & 1 & & 1 & \\
\hline Cart & & 314 & $57(18.2)$ & $1.5(0.6,3.3)$ & 0.401 & $3.9(0.1,91.7)$ & 0.723 \\
\hline & Draft & 42 & $13(31.0)$ & $1.2(0.4,3.7)$ & 0.709 & $1.1(0.3,5.3)$ & 0.919 \\
\hline
\end{tabular}

Riding

\begin{tabular}{cllllll} 
Season January & 64 & $3.0(4.7)$ & 1 & & 1 & \\
& 142 & $22(15.5)$ & $1.5(2.2,3.5)$ & 0.300 & $1.2(0.4,3.4)$ & 0.730 \\
December & 50 & $11(22.0)$ & $1.6(0.7,3.8)$ & 0.334 & $2.4(0.7,8.2)$ & 0.187 \\
& 64 & $20(31.3)$ & $1.7(0.7,4.0)$ & 0.203 & $2.4(0.8,7.5)$ & 0.135 \\
November & 64 & $21(32.8)$ & $0.9(1.5,21.9)$ & 0.013 & $7.6(1.6,32.0)$ & 0.012 \\
February & & & & & \\
March & & & & & \\
\hline
\end{tabular}

\section{Discussion}

The overall lungworm infection prevalence of $20.1 \%$ recorded in the current study is in agreement with some of the previous reports. Different prevalence reports of $D$. arnfieldi were reported by various researchers from Ethiopia. [15] and [16] reported a prevalence of $20 \%$ in Bale and $23.2 \%$ in Wonchi district, respectively. However lower prevalence (13.80\%) or lungworm infection was reported by [17] in and around Jimma town. These differences in prevalence might be due to differences in management practice favoring the survival of the larvae of the parasite and environmental conditions.

The prevalence of lungworm infection in horses $(31 \%)$ was greater than in mules $(24.1 \%)$ and donkeys $(18.21 \%)$. The relatively higher prevalence in horses might be attributed to the difference in the purpose of these animals which means that in the study area most of the horses are used for riding (sport) purpose only during the Holy day and hence they pass most of their time grazing on fields which increase chance of acquiring infection than donkeys and mules. The other reason could be due to the lower number of samples in case of horses and mules in the current study may also affect the infection rate of these species. The prevalence report in horse in the current study is lower than the $38 \%$ prevalence of $D$. arnfieldi reported by [18] in Kentucky in horses. However, lower prevalence of $4.3 \%$ in horses of $D$. arnfieldi was reported by [17] and (10.4\%) reported by [19] in Denmark. These differences in prevalence might be due to differences in agro ecology, management practice favoring the survival of the larvae of the larvae of the parasite, and in environmental condition.

The present prevalence of lungworm infection in donkeys $(18.21 \%)$ is agreement with report (16.2\%) of [20]and higher than (3.6\%) finding of [21] in and around Hawassa and $(9.67 \%)$ reported by [22] in Turkey. But it was lower than previous findings of [23] who described a prevalence of $30.5 \%$ and $32.8 \%$ in Dire Dawa and other Eastern parts of the country, 
respectively. [24] reported (32\%) prevalence of dictyocalus arnfieldi in donkeys in Dugda Bora District. [25] reported (42.8\%) in donkeys of Sululta and Gefersa District. Higher prevalence of Dictyocaulus arnfieldi also reported in donkey by [11], [2] and [26] who recorded the value of $48 \%, 83 \%$ and $70.5 \%$, Morocco, Ethiopia and Sudan, respectively. And extremely higher prevalence $(87.5 \%)$ larva of $D$. arnfieldi in Denmark was found in donkeys by [19] and (51\%) was reported from Netherland by [27]. These differences might be due to differences in agro ecology, season and sample size.

The present prevalence of lungworm infection in mule $(24.1 \%)$ and was slightly lower than the $29.27 \%$ reports of [17] while it is slightly higher than the $20 \%$ prevalence reports by [28] in and around Bahir Dar. Similarly, a higher prevalence of lungworm was reported by [18] in donkeys and mules (54\%) in Kentucky, USA. Lower prevalence of lung worm infection (7\%) in mule was also reported by [3].

In this study the age animals was found as a major factor for variation in prevalence of lungworm infection. The highest prevalence (28.7\%) was recorded in young (less than 5 years) and $(20 \%)$ in old (more than 11 years) age groups. This might be related to the condition that older and younger animals are taught to have decreased immunity. Different levels of prevalence were observed in different body condition score. A prevalence of 35.5\%, 18.4\%, and 14\% were recorded in poor, medium and good body condition scores respectively. Animals with poor body conditions are more susceptible to lungworm infection than animals with good body condition.

The significantly higher prevalence observed in males (24.6\%) than in females (19.3\%) observed by the univariate analysis could be due to the relatively higher work load for males than for females.

Concerning the seasonality of infection, in the current study it was found that the prevalence of infection was high in March (32.8\%) and February (31.25\%) than the rest of the study months. The environmental condition during these two months is relatively favorable due to the better rain availability while the rest months are not as they are relatively day. Hence, during this adverse climatic condition larvae of lungworm prefer to inhibit in the lung tissue and mature at the begging of the rainy season.

\section{Conclusion and Recommendation}

In general this study reveals the occurrence of highest prevalence of lungworm infection in horses when compared to that of mule and donkey. However, this difference was not found to be significant. Concerning the risk factors analysis, the lungworm infection was significantly higher among the young ( $<5$ years) and very old animals $(>11$ years), among the animals with poor body condition and in months of March and February. Additionally, higher occurrence of lungworm was recorded among males than females and in kebele 3 based on the univariate analysis. 
Based on the above conclusion the following recommendations are for warded.

1) Attention should be given on the animals for the young and very old animals as they are more susceptible to the infection of lungworm. Hence, they should be dewormed and nourished well.

2) If possible the grazing field of donkeys and horses should be different

3) In general awareness should be created to the owners regarding the management system of equine.

\section{References}

[1] CSA, (2013). Livestock and livestock characteristics. Agricultural sample survey 2012/13. Volume II.

[2] Feseha, G. A., Mohammed, A., \& Yilma, J. M. (1991). Vermicular endoparasitism in donkeys of Debre-Zeit and Menagesha, Ethiopia: Strategic treatment with ivermectin and fenbendazole. In Donkeys, mules \& horses in tropical agricultural development: proc of a Colloquium organ by the Edinburgh School of Agric \& the Cent for Trop Vet Med of the Univ of Edinburgh \& held in Edinburgh, Scotland, 3rd-6th Sept 1990. [Edinburgh]: Centre for Tropical Veterinary Medicine, c1991.

[3] Sapakota, C. R. (2009). A Report on Prevalence of Helminthes Parasites in Mules of Brick Kiln P. 160.

[4] Svendsen, E.D. (1997). The professional Hand book of the Donkey. 3rd ed. White Books LTD, W, 40BY, London.

[5] Mulate, B, (2005). Preliminary study on Heliminthosis of equine in South and North Wollo Zone, Ethiopia. Vet. J. 9(2). PP. 27-29.

[6] Urquhart, G.M., Armour, J., Juncan, J.L., Dunn, A.M., Jennings, F.W. (1996). Veterinary parasitology. 2nd ed. Blackwell science Ltd.

[7] Briggs, K., Reinmeyer, C., Reimeyer, D. Kaplan, K. (2004). Parasite primary part 5- Bots and Beyond. Little known parasite Enenemics.The horse, PP. 19-22

[8] Matthew, J.B. (2002). Parasitic Air way disease. In: P.Lekeux (Ed.). Equine Respiratory disease. International Veterinary Information Service (eee.Ivis.Org). Ithaca, New York. USA.

[9] Mandal, S.C. (2006). Veterinary parasitology, 1stedi. Charbegh, India

[10] Higgins, A. J., \& Snyder, J. R. (Eds.). (2013). The equine manual. Elsevier Health Sciences.

[11] Pendey, V.S. (1980). Epidemiological Observation on lungworm Dictyocaulus arnfieldi in donkeys from Morocco. Journal of Helminthology, 54, pp. 275-277.

[12] Alemu, S., Leykun, E.G., Ayele, G., Zeleke, A. (2006). Study on Small ruminat lungworm in North Eastern Ethiopia. Verrinary Parasitology.

[13] Thru field (1995). Veterinary epidemiology. 2nd University of Edinburgh Blackwell Science Ltd PP. 180-182

[14] MARD, (2005). Standard Veterinary Parasitology Laboratory Diagnostic Manual of the Ministry of Agriculture and Rural Development, The National Animal Health Department, Addis Ababa, Ethiopia, pp: 4-6.

[15] Getahun, F. (1993). Helminths and external parasites of equines species in Bale Administrative Region, Ethiopia.

[16] Shiferaw, Y. (1993). Preliminary survey on heliminthosis and management practice of equine in Wenchi Awraga, Ethiopia

[17] Solomon, T., Bogale, B., Chanie, M., \& Melaku, A. (2012). Occurrence of lungworm infection in equines and their associated risk factors. Glob. Vet, 8, pp. 35-38.

[18] Lyons, E.T, Tolliver, S.C. Drudge J.H, Swerezek.T, Crowe. M.W. (1985). Lungworms (Dictyocaulus arnfieldi) prevalence in live equids in Kentucky American J. Veterinary Res., 46: 9-21. 
[19] Andersen, S. and Fogh. J, (2010). Prevaleence of lungworm D. arnfieldi in Denmark in donkeys and horses in herds together with donkeys. Nord Veterinary Medicine.

[20] Beelitz, P., Göbel, E., \& Gothe, R. (1996). Endoparasites of donkeys and horses kept in communal housing in Upper Bavaria; species spectrum and incidence. Tierarztliche Praxis, 24(5), 471-475.

[21] Ibrahim, N., Berhanu, T., Deressa, B., \& Tolosa, T. (2011). Survey of prevalence of helminth parasites of donkeys in and around Hawassa town, Southern Ethiopia. Glob Vet, 6(3), 223-227.

[22] Inasi Umur and Mustafa Acici. (2009). A survey on helminth infections of equines in the Central Black Sea region, Turkey. Turk. J. Vet. Anim. Sci, 33:373-378.

[23] Legese, Y., (1996). Preliminary survey on management aspects and health problem of donkey in Dire Dawa and East Oromia, Ethiopia.

[24] Ayele, G., Feseha, G., Bojia, E., \& Joe, A. (2006). Prevalence of gastro-intestinal parasites of donkeys in Dugda Bora District, Ethiopia. Livestock research for rural development, 18(10), 1421.

[25] Asefa, Z., Kumsa, B., Endebu, B., Gizachew, A., Merga, T., \& Debela, E. (2011). Endoparasites of donkeys in Sululta and Gefersa districts of Central Oromia, Ethiopia. J Anim Vet Adv, 10(14), $1850-1854$.

[26] Seri, H. I., Hassan, T., Salih, M. M., \& Abakar, A. D. (2004). A Survey of Gastrointestinal Nematodes of Donkeys (Equus asinus) in Khartoum State, Sudan. Journal of Animal and Veterinary Advances.

[27] Boersema, J. H., Kalis, C. H. (1978). Survey of the incidence of Dictyocaulus arnfieldi infections in donkeys in the Netherlands (author's transl). Tijdschrift voor diergeneeskunde, 103(19), 9981001.

[28] Esheta, G., (2000). Preliminary survey on the health and reproductive status of Gari Mules in and around Bahir Dar.

*Corresponding author.

E-mail address: tolesanegasa21@gmail.com 